Gut, 1962, 3, 273

\title{
A new direct-vision biopsy gastroscope
}

\author{
Ch. DEBRAY, P. HOUSSET, E. MARTIN, J. P. BOURDAIS, \\ AND C. L. NICOLAIDIS
}

From the Bichat Hospital, Paris

EDITORIAL SYNOPSIS Experience of 70 gastroscopies with direct-vision biopsy is favourable and indicates that this instrument will be of great assistance in certain difficult diagnostic problems of gastric pathology.

Endoscopy in general loses some of its diagnostic value if not completed by a biopsy taken from a definitely chosen area of the suspected lesion. Gastroscopy is no exception to this rule but it is only since 1940, when Kenamore introduced his direct-vision biopsy gastroscope, that this problem was solved. Since then many scientists have studied the problem. In 1947, in France, Camena d'Almeida introduced a new type of instrument, followed, in 1948, by the operating gastroscope introduced in the United States by Benedict, used at the present time in most American and European countries (Benedict, 1950a; Wiebenga, 1951).

The aspiration-section tube, introduced in 1949 by Wood and his collaborators in Australia and by Debray and Housset in France, found scientists almost unanimously agreed that the specimens of the gastric mucosa obtained by this method were superior to those obtained by forceps (Wood, Doig, Motteram, and Hughes, 1949; Debray, Housset, and d'Autray-Tarte, 1953; Debray, Laumonier, and Housset, 1953). The results of examination of such specimens taken from an unspecified region of the gastric mucosa are of value for diffuse lesions of the stomach only and they give no histological information about a localized lesion, nor can they help in the evaluation of ulcerated or proliferating lesions seen during gastroscopic examination. Consequently to benefit from the advantages and to overcome the disadvantages of this instrument, Tomenius (1952), combined it with a gastroscope and Hancock mounted the aspiration-section tube, as modified by Shiner, onto a Hermon Taylor gastroscope (Hancock and Shiner, 1958; Shiner, 1956). Then Debray and Housset, after a long series of trials, introduced a new type of direct-vision biopsy gastroscope based on the principle of aspiration-section (Debray and Housset, 1959; Debray, Housset, and Martin, 1960; de Gramont, Debray, and Housset, 1959; Bourdais, 1960; Nicolaidis, 1961).

\section{APPARATUS AND TECHNIQUE}

The apparatus consists of an ordinary gastroscope carrying a removable aspiration-section gastric biopsy tube. It has the same qualities as the ordinary gastroscope, its entire distal end being flexible. The biopsy tube consists of a rigid part, $3 \mathrm{~mm}$. in diameter, attached to the metallic part of the gastroscope by an easily unfastened junction ring, extended by a softer part, $3.5 \mathrm{~mm}$. in diameter, which runs within a cylindrical tunnel formed by the plastic material of the gastroscope's flexible smooth sheath (Fig. 1). The diameter of the rigid part is $7.2 \mathrm{~mm}$., in contrast to the $8.2 \mathrm{~mm}$. of the ordinary gastroscope. The flexible part is a little larger, forming an oval shape whose axes are $11.2 \times 15.3 \mathrm{~mm}$. in contrast to the constant $11.2 \mathrm{~mm}$. diameter of the standard gastroscope. To obtain these dimensions and at the same time keep the standard visual field of $90^{\circ}$, the diameter of the optical lens had to be notably reduced.

At the outlet of the cylindrical tunnel, the head of the biopsy tube fits into a double-armed lever which helps, by means of force applied to the proximal end of the tube, to abduct it from the instrument and place it in contact

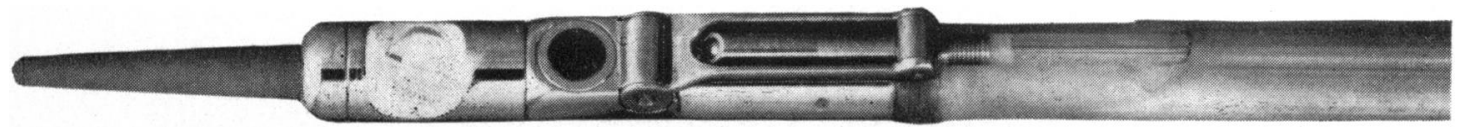

FIG. 1. Distal part of the instrument. The biopsy tube rests on the gastroscope. Original position for the introduction and removal of the apparatus. 


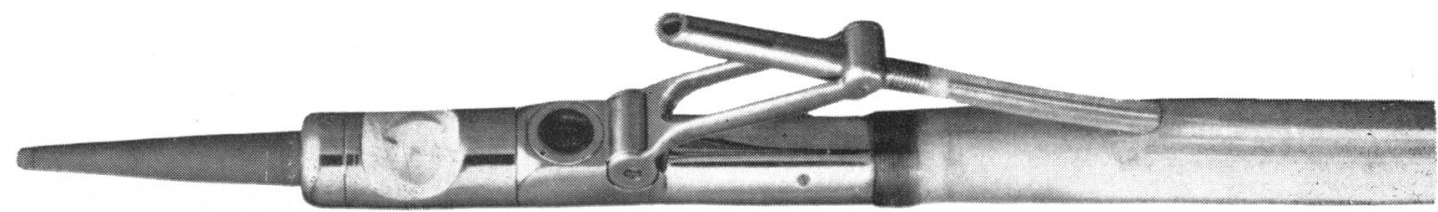

FIG. 2

FIG. 2. Distal part of the instrument. The head of the biopsy tube is abducted from the gastroscope and lies within the visual field of the apparatus.

FIG. 3. Proximal part of the instrument. The eye piece of the gastroscope and the proximal end of the biopsy tube bearing on its side the aspiration valve.

with the stomach wall. The position of the lever in relation to the object lens makes the head of the biopsy tube fall within the visual field of the gastroscope (Figs. 2 and 3).

The biopsy system rests on the principle of aspirationsection. The vacuum formed in the tube draws the gastric mucosa or the tumoral tissue in contact with the head of the biopsy tube into its circular aperture, $2.5 \mathrm{~mm}$. in diameter; an interior biopsy knife, which is guided by the proximal end of a silver wire lying in the axes of the tube, cuts the aspirated tissue. The biopsy is not done laterally as is the case with the ordinary flexible biopsy tube but at the distal end of the instrument and the mucosa is sectioned by rotating the biopsy knife and not by traction running from tail to head.

After having removed the instrument and unscrewed the terminal capsule of the biopsy tube, the specimens are easily collected from a 'reception chamber' in which they accumulate by the force of aspiration.

All the pieces that compose the instrument have been bevelled so as to avoid damaging the mucosa either during its introduction or during its removal. The lever has been designed in such a way as to prevent the mucosa being pinched either between its arms or between the lever and the biopsy tube at any time during manipulation.

To localize the spot from which a specimen is to be taken, air must be injected into the gastric cavity by means of a long rubber tube introduced into the stomach before the gastroscope.

During the introduction of the instrument the biopsy tube is pulled slightly to prevent protrusions. Once the gastroscope is in place and the biopsy tube is required, slight pressure applied at its proximal end will abduct the tube and place it within the visual field in contact with the gastric mucosa of the area where a biopsy is to be performed. Aspiration is achieved by means of a simple water vacuum pump adapted to the aspiration valve of the instrument located near the eye piece. The rotation of the biopsy knife manoeuvred by the proximal end of the instrument cuts the aspirated specimen, an operation which can be repeated at will.

The operation finished, slight traction on the proximal end of the biopsy tube will bring it back to its initial place in contact with the gastroscope. The instrument

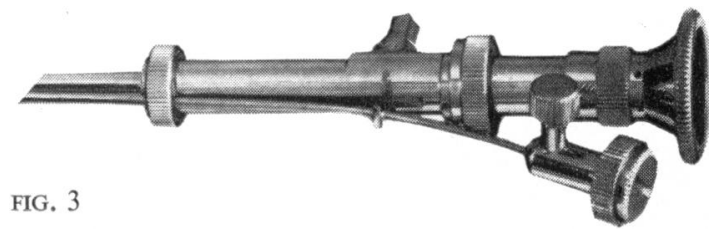

can now be removed, and the specimens collected and treated according to the usual procedures. It is interesting to note that the smears or secretions aspirated during the course of the operation can be collected either directly from the biopsy tube or from a bottle placed somewhere along the aspiration system. This material provides for a complementary cytological examination which we call 'direct-vision cytodiagnosis'.

\section{RESULTS}

Our experience with this instrument is at present limited. We have performed 70 gastroscopies, during which more than 100 specimens of gastric mucosa were obtained without mishap. In 19 cases $(27 \%)$ a biopsy could not be done for various reasons: technical failure, obstruction at the cardia, insufficient cooperation by the patient. Of a total of 51 specimens, $44(86 \cdot 2 \%)$ were considered adequate for histological study and seven $(13.7 \%)$, were regarded as unsatisfactory. In 18 cases we have obtained a direct-vision cytodiagnosis (Table I).

TABLE I

\section{OVERALL RESULTS IN 70 GASTRIC BIOPSIES}

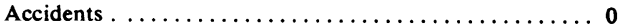

Technical failures.......................

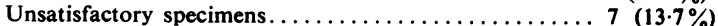

Satisfactory specimens...................44 (86.2\%)

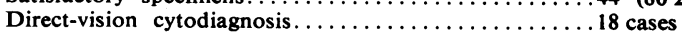

${ }^{1}$ Before 1959 , representing $57.6 \%$ and after 1959 , representing $9.0 \%$.

In 33 cases of carcinoma verified histologically after operation or at necropsy, the biopsy permitted a definite diagnosis in 16 cases $(48.4 \%)$; it was negative in seven cases $(21 \cdot 2 \%)$; and it was doubtful in one case. In this same group a biopsy specimen could not be obtained in five cases $(15.1 \%)$ and inadequate specimens were obtained inanother four $(12.1 \%)$. A cytodiagnosis was performed in 15 cases, 


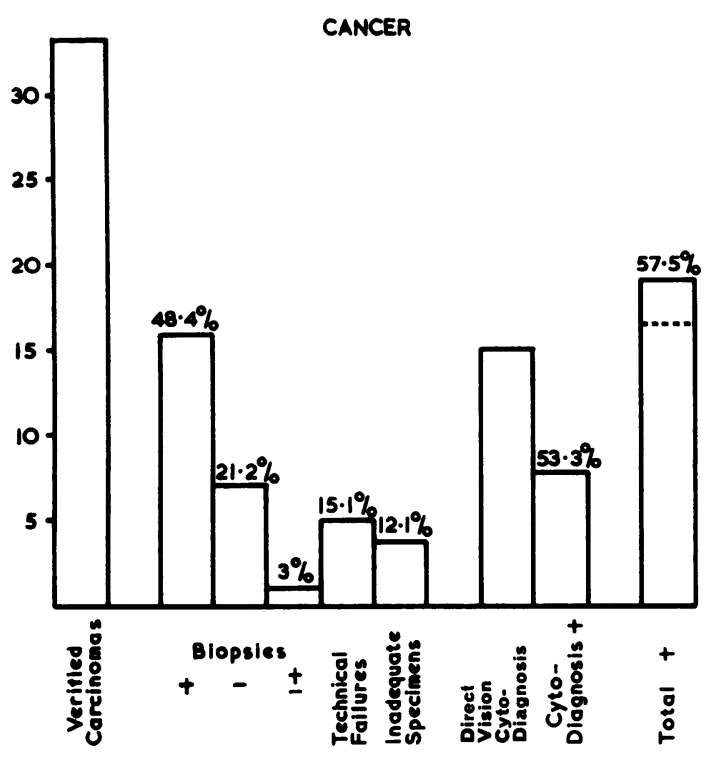

FIG. 4. Graphic representation of the results obtained by direct-vision biopsy and direct-vision cytodiagnosis in 33 cases of gastric carcinoma.

of which eight were positive $(53.3 \%)$. The diagnosis of malignancy was definitely made either by biopsy or by direct-vision cytodiagnosis in 19 cases $(57.5 \%)$ (Fig. 4).

As far as peptic ulcer is concerned, 19 cases were verified as benign either by post-operative histological examination or in the course of the disease. In nine cases $(47 \%)$, histological examination of the specimens showed a normal mucosa in one of them $(5 \%)$ and a gastritis in the other eight cases. It proved that the biopsy was performed at the edge

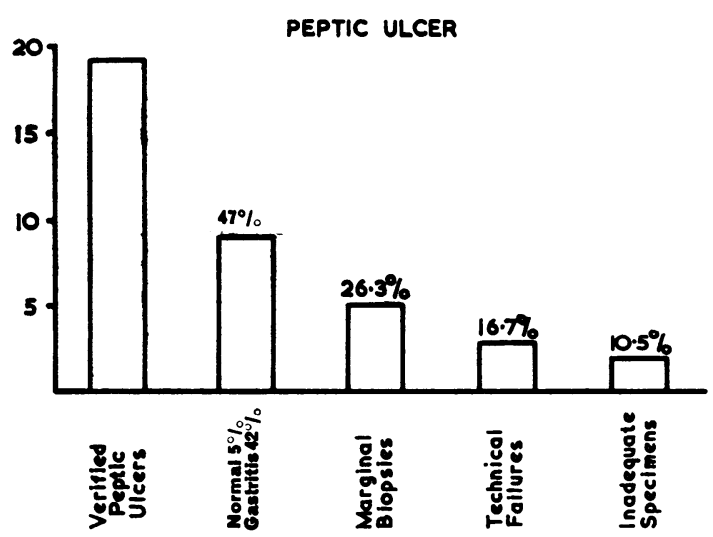

FIG. 5. Graphic representation of the results obtained by direct-vision biopsy in 19 cases of peptic ulcer. of a peptic ulcer in five cases $(26 \cdot 3 \%)$. No biopsy was possible in three cases $(16.7 \%)$ while in another two $(10.5 \%)$ the specimens were considered inadequate (Fig. 5).

\section{DISCUSSION}

The number of failures may at first sight appear very great but it must be appreciated that these numbers cover a period of long trials during which a series of technical modifications was made on the instrument. On the other hand the technique is new and delicate, necessitating a period of training. Consequently the percentage of failures during the years 1954 to 1959 amounted to $57.6 \%$ of the gastroscopies, whereas after that time the percentage of failures has only been 9 . These figures explain why a significant number of inadequate specimens and negative biopsies was recorded in the group of carcinomas, provided that the results refer to the whole period during which experiments with the new instrument were done.

The small number of cases that have been studied during the course of seven years is due to the fact that gastric biopsy was used only in cases where it was difficult to differentiate between malignancy and benignity by means of the usual methods.

The value of direct-vision biopsy and direct-vision cytodiagnosis varies from case to case. When the clinical and radiological examination and gastroscopy leave no doubt about the diagnosis, the biopsy or cytodiagnosis has only a confirming value (seven cases) but when a doubt arises during the clinical and $x$-ray examination as to the malignancy of the lesion, and gastroscopy reveals a suspicious lesion, these two diagnostic methods acquire a fundamental importance (nine cases). Their greatest value is when the clinical and $x$-ray examinations as well as the gastroscopy provide no definite diagnosis. In three of our cases only the biopsy has shown the existence of a carcinoma, as demonstrated in the following case report.

In a woman aged 50 years a biopsy was done in January 1961. Clinically the patient presented a typical ulcer syndrome. In radiographs taken one and one and a half years before the stomach appeared normal but another series taken one month before the biopsy showed radiation of the gastric folds towards a possible crater on the lesser curvature. A gastroscopic examination at that time showed two typical ulcers. In a new series of radiographs taken a month after treatment was begun there was a considerable regression of the previous findings, and gastroscopy performed at the same time showed a complete recovery of the lesions. A biopsy was, however, performed and histological examination of the specimens showed an epithelioma. 
During the operation the surgeon could see or palpate nothing on the outer part of the stomach wall but histology of the resected stomach confirmed the diagnosis of carcinoma.

In cases like the above direct-vision biopsy undoubtedly plays a primary role in indicating surgical treatment which, at this time, will give the best possible results.

Our experience and results reported in the literature allow us to reach certain conclusions as to the advantages and disadvantages of our method (Benedict, 1950b, 1951, 1955; Gondard, 1956; Shallemberger, DeWan, Weed, and Reganis, 1951; Ylvisaker, Carey, Myhre, and Carey, 1955; Nicolaidis, 1961).

The percentage of positive results which we obtained in the detection of cancer by direct-vision biopsy based on the principle of aspiration-section is higher than any other reported series, most of which were obtained by a direct-vision biopsy gastroscope based on the principle of biopsy by forceps. Also the majority of scientists who have experimented with direct-vision biopsy have studied the differential diagnosis of different types of gastritis, except Wirts, Carroll, and Wald (1951) who published a study almost identical with ours.

The advantages of our method appear to be the following:-

The relatively reduced diameter of the rigid part of the gastroscope facilitates its introduction and makes manipulation easier than with the instruments generally used. The principle of section by aspiration provides specimens which are uniformly cut and limited in surface and depth and several specimens can be taken successively. Direct-vision biopsy and direct-vision cytodiagnosis can be performed simultaneously through the same tube. The handling of the biopsy tube is simple, its orientation by the double-armed lever avoids all lateral displacement of the head of the biopsy tube during the operation and increases the possibility of precise biopsy.

Like all apparatus, this instrument presents some defects and inconveniences. It is larger in its flexible part than the ordinary gastroscope and certain regions of the stomach are difficult to reach. The handling of the gastroscope calls for training. It is fragile and needs to be carefully used.
Finally, as with all other biopsies, a negative result has no diagnostic significance, for the specimens might have been taken from a non-malignant region.

\section{REFERENCES}

Benedict, E. B. (1948). An operating gastroscope. Gastroenterology' 11, 281-283.

(1950a). Value of gastric biopsy specimens obtained through the flexible operating gastroscope. Arch. Path., 49, 538-544.

(1950b). The differential diagnosis of benign and malignant lesions of the stomach by means of the flexible operating gastroscope. Gastroenterology, 14, 275-279.

(1951). Gastroscopic biopsy in the differential diagnosis of gastritis and carcinoma. New Engl. J. Med., 245, 203-206.

(1955). Gastroscopy with biopsy: differential diagnosis of carcinoma of the stomach. Missouri Med., 52, 23-25.

Bourdais, J. P. (1960). Dangers et insuffisances de la gastroscopie. Statistique sur 7237 observations. Mémoire, Paris.

Camena d'Almeida. P. (1947). La biopsie de la muqueuse gastrique. Presse méd., 55, 558.

Debray, Ch., Housset, P., and d'Autray-Tarte, P. (1953). La biopsie de la muqueuse gastrique. Appareillages et techniques-indications. Sem. Hóp. (Paris), 29, 2009-2017.

- Laumonier, R., and Housset, P. (1953). Biopsie par "aspirationsection" de la muqueuse gastrique et aspects gastroscopiques. lbid., 29, 2018.2027.

_- and Housset, P. (1959). Sur la gastrobiopsie dirigée. Présentation d'un nouveau gastroscope biopsique. Arch. Mal. Appar. dig., 48, 1111-1117.

$\longrightarrow$, $\longrightarrow$ and Martin, E. (1960). Nouvelle technique de gastrobiopsie dirigée sous contrôle gastroscopique. Interêt dans le diagnostic du cancer de l'estomac. Acta gastro-ent. belg., 23. 937-942.

Gondard, L. (1956). Gastrobiopsie dirigée. Quelques cas personnels. Arch. Mal. Appar. dig., 45 (2), 373-376.

de Gramont, A., Debray, C., and Housset, P. (1959). La biopsie gastrique dirigée. C. R. Acad. Sci. (Paris), 248, 3379-3380.

Hancock, P. E. T., and Shiner, M. (1958). Combined gastroscopy and gastric biopsy under direct vision. Lancet, 1, 1204-1205.

Kenamore, B. (1940). A biopsy forceps for the flexible gastroscope. Amer. J. dig. Dis., 7, 539.

Nicolaidis, C. L. (1961). La gastrobiopsie dirigée avec l'appareil par "aspiration-section" de Debray et Housset. Son interêt pour le dépistage des lísions localisées de l'estomac. Mémoire, Paris.

Shallenberger, P. L., Dewan, C. H., Weed, C. B., and Reganis, J. C. (1951). Gastroscopic biopsy. Correlation of clinical findings and tissue biopsies of the stomach. Rev. Gastroent., 18, 348-365.

Shiner, M. (1956). Gastric biopsy under direct visual control with the Hermon Taylor gastroscope. Lancet, 2, 173.

Tomenius, J. (1952). A new instrument for gastric biopsies under visual control. Gastroenterology, 21, 544-546.

Wiebenga, A. H. (1951). Gastroscopie en gastrobiopsie. De Erven F. Bohn, Haarlem.

Wirts, C. W., Carroll, J. L., and Wald, D. (1951). Experience with the operating gastroscope. Gastroenterology, 19, 777-786.

Wood, I. J., Doig, R. K., Motteram, R., and Hughes, A. (1949). Gastric biopsy; report on fifty-five biopsies using a new flexible gastric biopsy tube. Lancet, 1, 18-21.

Ylvisaker, R. S., Carey, J. B., Myhre, J., and Carey, J. B. Jr. (1955) Biopsy studies of the gastric mucosa. Gastroenterology, 28, 88-102. 